\title{
Impact of the definition of osteoarthritis and of the timing of its onset on the association between type 2 diabetes mellitus and osteoarthritis
}

Citation for published version (APA):

Nielen, J. T. H., Dagnelie, P. C., Boonen, A., Klungel, O., van den Bemt, B., \& de Vries, F. (2019). Impact of the definition of osteoarthritis and of the timing of its onset on the association between type 2 diabetes mellitus and osteoarthritis: Clinical Practice Research Datalink. Diabetes Research and Clinical Practice, 148, 240-248. https://doi.org/10.1016/j.diabres.2019.01.021

Document status and date:

Published: 01/02/2019

DOI:

10.1016/j.diabres.2019.01.021

Document Version:

Publisher's PDF, also known as Version of record

Document license:

Taverne

Please check the document version of this publication:

- A submitted manuscript is the version of the article upon submission and before peer-review. There can be important differences between the submitted version and the official published version of record.

People interested in the research are advised to contact the author for the final version of the publication, or visit the DOI to the publisher's website.

- The final author version and the galley proof are versions of the publication after peer review.

- The final published version features the final layout of the paper including the volume, issue and page numbers.

Link to publication

\footnotetext{
General rights rights.

- You may freely distribute the URL identifying the publication in the public portal. please follow below link for the End User Agreement:

www.umlib.nl/taverne-license

Take down policy

If you believe that this document breaches copyright please contact us at:

repository@maastrichtuniversity.nl

providing details and we will investigate your claim.
}

Copyright and moral rights for the publications made accessible in the public portal are retained by the authors and/or other copyright owners and it is a condition of accessing publications that users recognise and abide by the legal requirements associated with these

- Users may download and print one copy of any publication from the public portal for the purpose of private study or research.

- You may not further distribute the material or use it for any profit-making activity or commercial gain

If the publication is distributed under the terms of Article $25 \mathrm{fa}$ of the Dutch Copyright Act, indicated by the "Taverne" license above, 


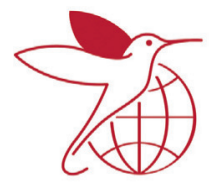

International

Diabetes

Federation

\title{
Impact of the definition of osteoarthritis and of the timing of its onset on the association between type 2 diabetes mellitus and osteoarthritis: Clinical Practice Research Datalink
}

\author{
Johannes T.H. Nielen ${ }^{a, b}$, Pieter C. Dagneliec, Annelies Boonen ${ }^{d}$, Olaf Klungel $^{a}$, \\ Bart van den Bemt ${ }^{e, f, g}$, Frank de Vries ${ }^{a, g, *}$ \\ ${ }^{a}$ Department of Pharmacoepidemiology \& Clinical Pharmacology, Utrecht University, Utrecht, the Netherlands \\ ${ }^{\mathrm{b}}$ Department of Epidemiology, CAPHRI School for Public Health and Primary Care, Maastricht University, Maastricht, the Netherlands \\ ${ }^{\mathrm{c}}$ Department of Epidemiology, CAPHRI School for Public Health and Primary Care, and CARIM School for Cardiovascular Diseases, \\ Maastricht University, Maastricht, the Netherlands \\ ${ }^{\mathrm{d}}$ Department of Internal Medicine, Division of Rheumatology, Maastricht University Medical Center+, Maastricht, the Netherlands \\ e Department of Pharmacy, Sint Maartenskliniek, Nijmegen, the Netherlands \\ ${ }^{\mathrm{f}}$ Department of Pharmacy, Radboud University Medical Center, Nijmegen, the Netherlands \\ ${ }^{g}$ Department of Clinical Pharmacy and Toxicology, Maastricht University Medical Center+, Maastricht, the Netherlands
}

\section{A R T I C L E I N F O}

Article history:

Received 19 October 2018

Received in revised form

27 December 2018

Accepted 15 January 2019

Available online 24 January 2019

Keywords:

Osteoarthritis

Diabetes mellitus

Total joint replacement

Methods

\begin{abstract}
A B S T R A C T
Aims: In a previous case-control study in a large primary care database, the Clinical Practice Research Datalink (CPRD), type 2 diabetes mellitus (T2DM) was associated with a decreased rate of total joint replacement (TJR). As this was in contrast to the hypothesis, selection bias due to the used definition of osteoarthritis (OA) or misclassification of the onset of OA were raised as possible explanations. We therefore aimed to explore the effect of the definition of $\mathrm{OA}$, and hypothesized timing of its onset on the association between T2DM and OA.

Methods: All patients using a non-insulin anti-hyperglycaemic drug (NIAD) between 1989 and 2012 in the CPRD were included and matched to unexposed patients. Cox proportional hazard models were fitted estimating the risk of TJR or OA in T2DM patients compared to patients without T2DM. These analyses were repeated in sensitivity scenarios and jointspecific analyses. To assess whether misclassification of onset of OA may affect the association, analyses were repeated with addition of a latency period of up to 10 years after start of follow-up.

Results: The use of TJR as a proxy for OA (hazard ratio (HR) = 0.74; 95\% Confidence Interval $(\mathrm{CI})=0.70-0.78)$ resulted in a HR that was approximately 0.2 lower than when OA diagnostic
\end{abstract}

\footnotetext{
${ }^{*}$ Corresponding author at: Division of Pharmacoepidemiology and Clinical Pharmacology, Utrecht Institute for Pharmaceutical Sciences, Utrecht University, the Netherlands.

E-mail address: f.devries@uu.nl (F. de Vries).
}

https://doi.org/10.1016/j.diabres.2019.01.021

0168-8227/@ 2019 Published by Elsevier B.V. 
codes were used $(\mathrm{HR}=0.93 ; 95 \% \mathrm{CI}=0.90-0.95)$. The joint-specific subgroup analyses, sensitivity scenarios, and latency analyses showed similar results.

Conclusion: When examining the association between T2DM and OA, the use of TJR as a proxy for OA resulted in a $20 \%$ lower estimate than the OA diagnosis.

(c) 2019 Published by Elsevier B.V.

\section{Introduction}

Osteoarthritis $(\mathrm{OA})$ is the main cause of pain and disability in the United Kingdom (UK), affecting around a third of people aged 45 years and older [1]. The most commonly affected joints are the knee and the hip [1]. When this disease progresses, pain and disability may deteriorate, and in patients with severe knee and hip OA, total joint replacement (TJR) may be the only remaining treatment option providing improvement of mobility, symptom relief, and quality of life [2].

Previous studies have suggested that type 2 diabetes mellitus (T2DM) may be an independent risk factor for OA [3-6]. However, in a recent case-control study we found a $15 \%$ reduced risk of TJR in T2DM patients compared to nonT2DM patients [7]. This study was conducted using a large primary care database, the UK Clinical Practice Research Datalink (CPRD). This database has the advantage of conducting studies on risk factors of diseases quickly and with low costs. Furthermore, the CPRD has been widely used to study risk factors of a variety of outcomes such as fractures, cardiovascular events, and mortality [8,9]. However, as coding for a diagnosis of OA is not yet validated in the CPRD, epidemiological studies have used TJR surgery (as proxy of severe OA) as the outcome of interest $[7,10]$. To the best of our knowledge, however, it has never been explored whether TJR is a reliable proxy of OA when conducting longitudinal studies of risk or effectiveness with OA as the outcome of interest. Generally, when using a proxy indicator of the outcome, the hazard function of the association under investigation, should reflect the intended hazard function as closely as possible. However, as TJR is likely to represent a subgroup of patients with more severe OA, TJR may not reflect OA and its hazard function properly. Consequently, the unexpected results obtained in our previous study may be the result of selection bias due to the use of TJR as proxy of OA.

In our previous study, patients with T2DM, especially those with severe T2DM, were possibly less eligible for TJR surgery due to an increased risk of surgical complications. For example, the risk of infection associated with surgery is higher in T2DM patients compared to patients who do not have T2DM [11]. More specifically, high HbA1c levels have been associated with more complications following TJR [12,13], and more surgical site infections in particular [14]. On a same line, HbA1c levels have been associated with increased mortality rates in non-orthopaedic surgical procedures [15]. Based on these reports of increased risks of potential surgical complications, surgeons may be less tempted to operate on patients with T2DM. Consequently, when TJR is used as a proxy for OA, patients with $\mathrm{OA}$ and high risk of surgical complications (and therefore do not undergo TJR) may be misclassified as non-OA patients.

In addition, timing of the onset of OA may be important when assessing the association between T2DM and OA. As the date of OA diagnosis is suggested to reflect the actual date of onset of the disease with an average delay of 7.7 years [16], and a T2DM diagnosis shortly before an OA diagnosis (or a TJR surgery) is unlikely to have influenced the course of OA substantially, misclassification of the date of onset of OA may result in biased estimates when assessing the association between T2DM and OA.

In short, due to selection bias or misclassification of the onset of OA, by using TJR as a proxy for OA, results may be biased. If these biases are indeed present the unexpected results from our previous study may be explained and use of TJR as proxy for OA should not be used in this setting. In order to evaluate the effect of these potential biases, we aimed to explore the effect of the definition of OA as outcome measure in the CPRD, and misclassification of its onset on the association between T2DM and OA. To determine the effect of the definition of the outcome, the risk of TJR or OA in T2DM patients compared to patients without T2DM was assessed. To evaluate whether misclassification of onset of OA may affect the association, we determined the effect of addition of a latency period of up to 10 years after start of follow-up.

\section{Methods}

\subsection{Data source}

A population-based cohort study was performed using the CPRD. The CPRD collates the computerized medical records of general practitioners (GPs) $[17,18]$. The data recorded in the CPRD include demographic information, prescription details, clinical events, preventive care provided, specialist referrals, and hospital admissions.

\subsection{Study population}

In the CPRD database, all patients aged 18 years or older who received their first non-insulin anti-hyperglycaemic drug (NIAD) prescription between January 1987 and October 2012 were selected. Follow-up started at the date of the first NIAD prescription. A period of at least one year between registration in the database and the first NIAD prescription was required. Patients with a recorded diagnosis of rheumatoid arthritis (RA) or hip/femur fracture ever before start of follow-up or during follow-up were excluded. Patients with an OA diagnosis or a recorded TJR prior to start of follow-up were also excluded. For each NIAD user, one patient not using 


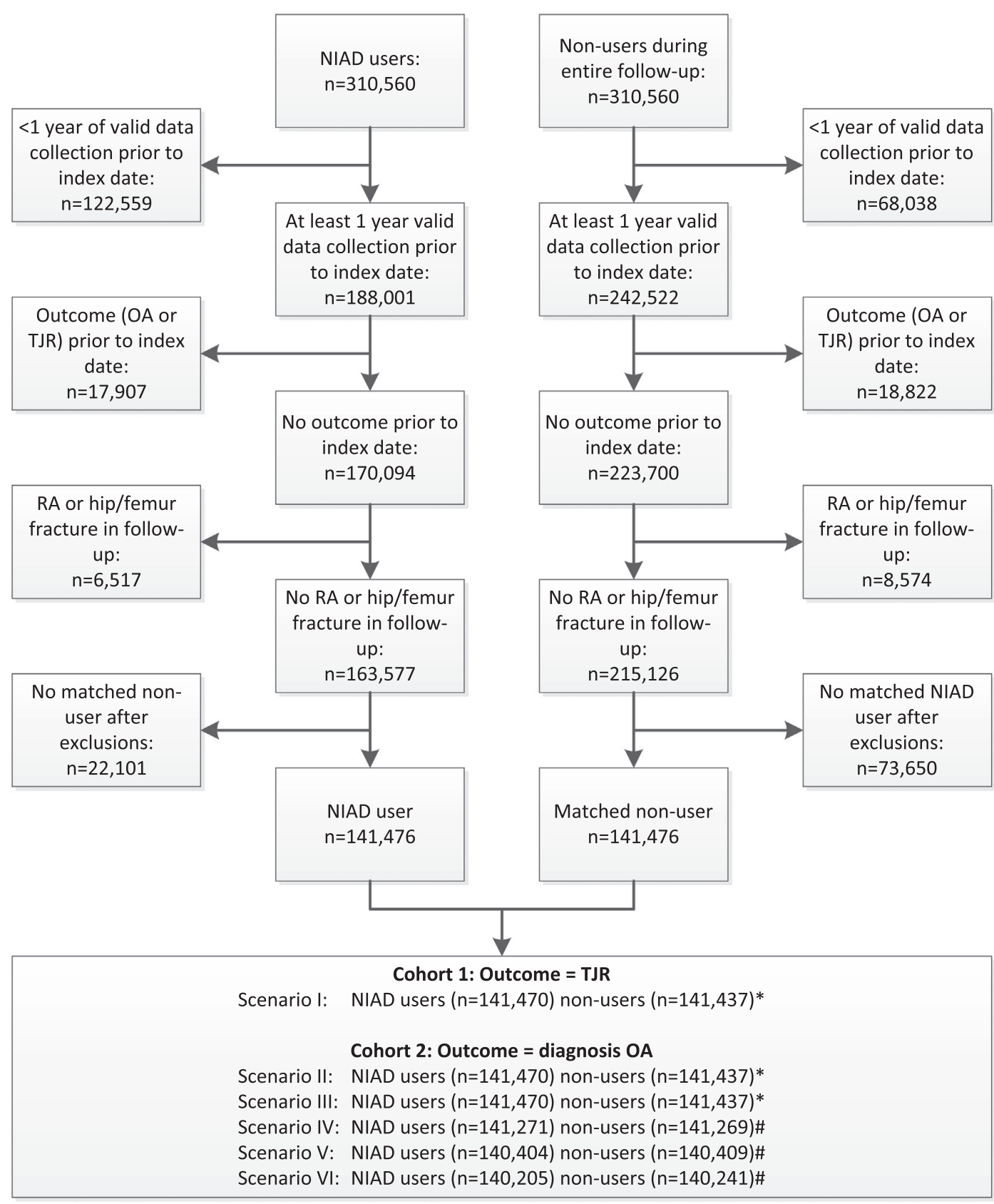

Fig. 1 - Exclusion flowchart. * Loss of patients due to lack of follow-up. \# Additional loss of patients due to exclusion of specific patient types (Scenario IV: patient type 5 excluded; Scenario V: patient type 3 excluded; Scenario VI: patient type 3 and 5 excluded). NIAD = non-insulin anti-hyperglycaemic drug, TJR = total joint replacement, OA = osteoarthritis.

a NIAD during the entire follow-up was selected and matched by year of birth, sex, and GP practice. The non-users started follow-up at the same date as their matched NIAD user (Fig. 1).

\subsection{Exposure}

Exposure to an incident NIAD prescription was used as a proxy for T2DM. NIADs included metformin, sulfonylurea, glucagon-like peptide-1 (GLP-1) analogues, dipeptidyl peptidase-4 (DPP-4) inhibitors, meglitinides, thiazolidinediones, or acarbose.

\subsection{Outcomes}

For data analysis, two cohorts were created based on the outcome: TJR (total knee replacement (TKR) or total hip replacement (THR); Cohort 1) on one hand, or a diagnosis of any OA (Cohort 2) registered by the GP on the other hand. In both cohorts, patients were followed up to either the end of data collection, the date of the patient's transfer out of the practice area, the patient's death, or the first registration of the outcome of interest. Within these cohorts, five potential types of patients were considered (Fig. 2). Type 1 patients had an OA diagnosis followed by a TJR later during follow-up. Type 
1

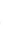

0

T

2

0

3 $\mathrm{T}$

$4 \longrightarrow$
$5 \longrightarrow \mathrm{T} \longrightarrow$
$\mathrm{O}=$ Osteoarthritis diagnosis

$T=$ Total joint replacement surgery

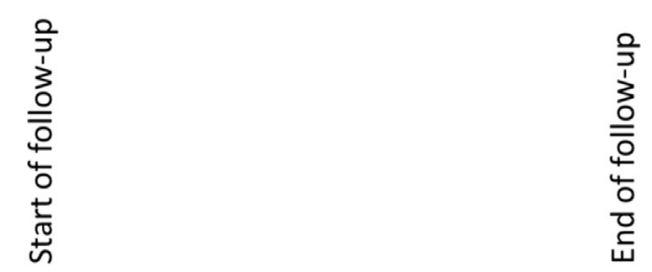

Fig. 2 - Potential patient types. Type $1(n=3133)$, Type $2(n=22,296)$, Type $3(n=2094)$, Type $4(n=255,062)$, Type $5(n=367)$.

2 patients only had an OA diagnosis during follow-up, and no TJR surgery. Type 3 patients only had a recording of TJR surgery during follow-up, and no OA diagnosis. Type 4 patients had no recordings of OA or TJR during follow-up. Type 5 patients had a recording of TJR surgery which was followed by an OA diagnosis during follow-up.

\subsection{Potential confounders}

Sex, age, and body mass index (BMI) at start of follow-up were considered as potential confounders.

\subsection{Statistical analysis}

Cox proportional hazard models were used to estimate the hazard ratios (HR) for the outcomes in patients with T2DM compared to patients without T2DM. Based on the abovementioned potential patient types (Fig. 2), six scenarios were analysed and are listed in detail in Table 1. In brief, we used the following analytical strategy: using six different scenarios, we moved stepwise from the original case-control study that used TJR surgery as the outcome [7], towards the scenario which may have had the lowest risk of bias and used an OA diagnosis as the outcome.

In scenario I, the risk of TJR was assessed while ignoring a potential record of an OA diagnosis. This analysis is comparable with a previous case-control study that was conducted within the largely same source population [7]. In this scenario, the outcome (TJR) occurred in patient types 1, 3, and 5 at some point during follow-up. In scenario II, the risk of an OA diagnosis while ignoring any potentially recorded TJR surgery was assessed. In this scenario, the outcome (OA diagnosis) occurred in patient types 1,2 , and 5 at some point during follow-up. In scenario III, the risk of an OA diagnosis was assessed while censoring patients at the date of TJR surgery if there was only a TJR (and no recorded OA diagnosis) or when TJR surgery had preceded the OA diagnosis. In this analysis, patient types 3 , and 5 were censored, and the outcome (OA diagnosis) occurred in patient types 1 and 2. In scenario IV, we used the same cohort as in scenario II, but now excluded patients with an OA diagnosis after TJR surgery (type 5 patients). Scenario $\mathrm{V}$ was another variation on scenario II, but now excluded all patients with TJR surgery during follow-up, who had no diagnosis of OA (type 3 patients). In scenario VI, the risk of an OA diagnosis was assessed while patients with a TJR surgery only (patient type 3 ), and patients with an TJR surgery prior to the OA diagnosis (patient type 5) were excluded (Table 1).

Cox proportional hazard models were also applied to determine the impact of misclassification of the date of onset of OA by adding a latency period up to 10 years after start of follow-up to scenario VI. In these models, patients with T2DM and patients without T2DM who experienced the outcome (OA diagnosis) within a specified latency period after start of follow-up were excluded from the analyses. As the date of OA diagnosis reflects the actual date of onset with an average delay of 7.7 years [16], we varied the latency period from 0 to 10 years after start of follow-up. A smoothing spline regression plot was drafted to visualise the effect of varying latency periods on the association between T2DM and OA in Scenario VI.

Subgroup analyses were conducted assessing the risk of joint-specific surgery (TKR and THR) and OA (knee OA (KOA), hip OA (HOA), or other OA) in six scenarios that were constructed in the same way as the primary analysis. Latency analyses were also conducted in these joint-specific sub- 


\section{Table 1 - Detailed information about six analytical scenarios.}

\begin{tabular}{|c|c|c|c|c|c|c|c|c|}
\hline \multirow[t]{2}{*}{ Scenario } & \multirow[t]{2}{*}{ Cohort } & \multirow[t]{2}{*}{ Outcome } & \multirow[t]{2}{*}{ Description } & \multicolumn{5}{|c|}{ Patient type (outcome in follow-up) } \\
\hline & & & & $\begin{array}{l}1 \text { (OA diagnosis } \\
\text { followed by TJR) }\end{array}$ & $\begin{array}{l}2 \text { (OA diagnosis } \\
\text { only) }\end{array}$ & 3 (TJR only) & $\begin{array}{l}4 \text { (no } \\
\text { outcome) }\end{array}$ & $\begin{array}{l}5 \text { (TJR followed } \\
\text { by OA diagnosis) }\end{array}$ \\
\hline I & 1 & TJR & $\begin{array}{l}\text { Similar to original analysis by Nielen et al. [5]. The } \\
\text { occurrence of an OA diagnosis any time during follow- } \\
\text { up was ignored (patient types } 1,2 \text {, and } 5 \text { ) }\end{array}$ & + & - & + & - & + \\
\hline II & 2 & $\mathrm{OA}$ & $\begin{array}{l}\text { The occurrence of a TJR any time during follow-up was } \\
\text { ignored (patient types } 1,3 \text {, and 5) }\end{array}$ & + & + & - & - & + \\
\hline III & 2 & $\mathrm{OA}$ & $\begin{array}{l}\text { Follow-up is censored at TJR if the patient only had a } \\
\text { TJR (patient type } 3 \text { ) or if the TJR preceded the OA } \\
\text { diagnosis (patient type 5) }\end{array}$ & + & + & - & - & - \\
\hline IV & 2 & $\mathrm{OA}$ & $\begin{array}{l}\text { Patients were excluded if the patient had a TJR that } \\
\text { was followed by an OA diagnosis (patient type 5). If the } \\
\text { patient only had a TJR then the TJR was ignored } \\
\text { (patient type 3) }\end{array}$ & + & + & - & - & Excluded \\
\hline V & 2 & $\mathrm{OA}$ & $\begin{array}{l}\text { Patients were excluded if the patient only had a TJR } \\
\text { (patient type } 3 \text { ). If a TJR was followed by an OA } \\
\text { diagnosis, then the TJR was ignored (patient type 5) }\end{array}$ & + & + & Excluded & - & + \\
\hline VI & 2 & $\mathrm{OA}$ & $\begin{array}{l}\text { Patients were excluded if the patient only had a TJR } \\
\text { (patient type3) or if the TJR preceded the OA diagnosis } \\
\text { (patient type 5) }\end{array}$ & + & + & Excluded & - & Excluded \\
\hline $\begin{array}{l}\text { Excluded } \\
+=\text { in this } \mathrm{p} \\
-=\text { in this } \mathrm{p} \\
\text { Patient type } \\
\text { Type 1: In th } \\
\text { Type 2: In th } \\
\text { Type 3: In th } \\
\text { Type 4: In th } \\
\text { Type 5: In th }\end{array}$ & $\begin{array}{l}\text { ient type } \\
\text { (Suppleme } \\
\text { patient ty } \\
\text { patient ty } \\
\text { patient ty } \\
\text { patient ty } \\
\text { patient ty }\end{array}$ & $\begin{array}{l}\text { e outcome } \\
\text { tary Fig. 1): } \\
\text { e, first an only an } \\
\text { e, only a TJ } \\
\text { e, no outco }\end{array}$ & $\begin{array}{l}\text { nt type was excluded from the analyses. } \\
\text { es occur. } \\
\text { oes not occur. } \\
\text { diagnosis was registered, followed by a TJR. } \\
\text { A diagnosis was registered. } \\
\text { was registered. } \\
\text { les occur during follow-up. } \\
\text { was registered, followed by an OA diagnosis. } \\
\text { ment OA = osteoarthritis. }\end{array}$ & & & & & \\
\hline
\end{tabular}


Table 2 - Baseline characteristics.

\begin{tabular}{|c|c|c|}
\hline Characteristic & $\begin{array}{l}\text { T2DM n }=141,476 \\
\mathrm{n}(\%)\end{array}$ & $\begin{array}{l}\text { No T2DM } n=141,476 \\
n(\%)\end{array}$ \\
\hline Age (years; mean (SD)) & $58.3(14.9)$ & $58.3(14.9)$ \\
\hline$<40$ & $17,857(12.6)$ & $17,857(12.6)$ \\
\hline $41-65$ & $76,165(53.8)$ & $76,165(53.8)$ \\
\hline$>65$ & $47,454(33.5)$ & $47,454(33.5)$ \\
\hline BMI $\left(\mathrm{kg} / \mathrm{m}^{2} ; \operatorname{mean}(\mathrm{SD})\right)$ & $31.4(6.7)$ & $26.7(5.0)$ \\
\hline$\leq 20$ & $1993(1.4)$ & $6961(4.9)$ \\
\hline $21-25$ & $18,442(13.0)$ & $42,895(30.3)$ \\
\hline $26-30$ & $45,257(32.0)$ & $47,098(33.3)$ \\
\hline$>30$ & $71,938(50.8)$ & $24,783(17.5)$ \\
\hline BMI missing & $3846(2.7)$ & 19,739 (14.0) \\
\hline Sex (female) & $63,860(45.1)$ & $63,860(45.1)$ \\
\hline Any outcome after start of follow-up & $14,678(10.4)$ & $13,212(9.3)$ \\
\hline TJR only after start of follow-up & $1066(0.8)$ & $1028(0.7)$ \\
\hline OA only after start of follow-up & $11,975(8.5)$ & $10,321(7.3)$ \\
\hline TJR and OA after start of follow-up & $1637(1.2)$ & $1863(1.3)$ \\
\hline
\end{tabular}

groups analyses. In all analyses, age, sex, and BMI adjusted estimates were calculated. SAS version 9.3 (PHREG procedure) was used for all analyses.

\section{Results}

Baseline characteristics of T2DM patients $(n=141,476)$ and patients without T2DM $(n=141,476)$ are presented in Table 2. On average both T2DM patients and patients without T2DM were 58.3 years of age, and $45.1 \%$ were female. T2DM patients had a mean BMI of $31.4 \mathrm{~kg} / \mathrm{m}^{2}$, versus $26.7 \mathrm{~kg} / \mathrm{m}^{2}$ for patients without T2DM. The T2DM patients were more likely to have either one of the outcomes (OA or TJR) in follow-up (10.4\%), as compared to the patients without T2DM (9.3\%).

The risk of TJR or OA for T2DM patients compared to patients without T2DM, determined in the various scenarios, is depicted in Table 3. The risk of TJR in scenario I ( $\mathrm{HR}=0.74$ [95\% Confidence Interval $(\mathrm{CI})=0.70-0.78]$ ), and the risk of OA in scenario II ( $\mathrm{HR}=0.93$ [95\% CI $=0.90-0.95]$ ) were both lower in T2DM patients compared to patients without T2DM. Furthermore, the HRs computed in the scenarios that censored follow-up at the date of TJR surgery (Scenario III), or excluded specific patient types with TJR surgery (Scenarios IV-VI) were largely comparable to the scenario without these restrictions (Scenario II). The results were similar in the joint-specific subgroup analyses.

The risk of any OA did not substantially change when a latency period up to 10 years after start of follow-up was added (Fig. 3). Similar results were found when a latency period was added to the joint-specific subgroup analyses (Supplementary Figs. 2-4).

\section{Discussion}

This study demonstrates that, when evaluating the association between T2DM and OA, the use of either a surgical or a diagnostic proxy of OA resulted in a reduced risk of the outcome. However, the risk of a TJR surgery was approximately $20 \%$ lower than the risk of an OA diagnosis for patients with
T2DM. Furthermore, by excluding and censoring patients with possible registration errors in a stepwise manner, a "close to ideal" study population was evaluated. The results of these scenarios (Scenarios III-VI) were similar to the primary scenario (Scenario II). The results were also similar in the joint-specific subgroup analyses. Overall, this may suggest that the use of TJR as a proxy for OA may introduce bias when assessing the association between T2DM and OA. Adding a latency period up to 10 years after start of follow-up did not change the results, which suggests that misclassification of start of onset of OA does not play a major role.

Our findings are partially in line with those from our previous case-control study which showed a $15 \%$ reduced risk (OR $=0.85 ; 95 \% \mathrm{CI}=0.76-0.94)$ of $\mathrm{TKR}$ and a $12 \%$ reduced risk (OR $=0.88 ; 95 \% \mathrm{CI}=0.83-0.94)$ of THR in patients with $\mathrm{T} 2 \mathrm{DM}$ compared to those without T2DM [7]. In the present study, the risks of TKR and THR were reduced by $23 \%$ ( $\mathrm{HR}=0.77$; 95\% CI $=0.72-0.84)$ and $30 \%(\mathrm{HR}=0.70 ; 95 \% \mathrm{CI}=0.65-0.76)$, respectively. The differences between these studies could be due to a difference in confounder adjustment. In the present study, the main objective was to determine whether there was a difference between a surgical and a diagnostic proxy of the outcome when assessing the association between T2DM and OA, rather than to assess the actual risk of T2DM on OA. Therefore, we did not include all potentially relevant confounders that were included in the previous case-control study. As a result, the current findings differ from those in our previous case-control study in a largely comparable study population.

In this study, the use of either a surgical or a diagnostic proxy for OA resulted in a reduced risk of the outcome in T2DM patients compared to subjects without T2DM. However, the HR for TJR was approximately $20 \%$ lower than the HR for the OA diagnosis. As suggested previously, this difference may have been caused by selection bias. Due to the presence of contraindicating comorbidities or risk factors, patients with T2DM may have a reduced eligibility to undergo elective joint surgery compared to patients without T2DM $[15,16]$. The reduced eligibility may be cause by an increased risk of infec- 


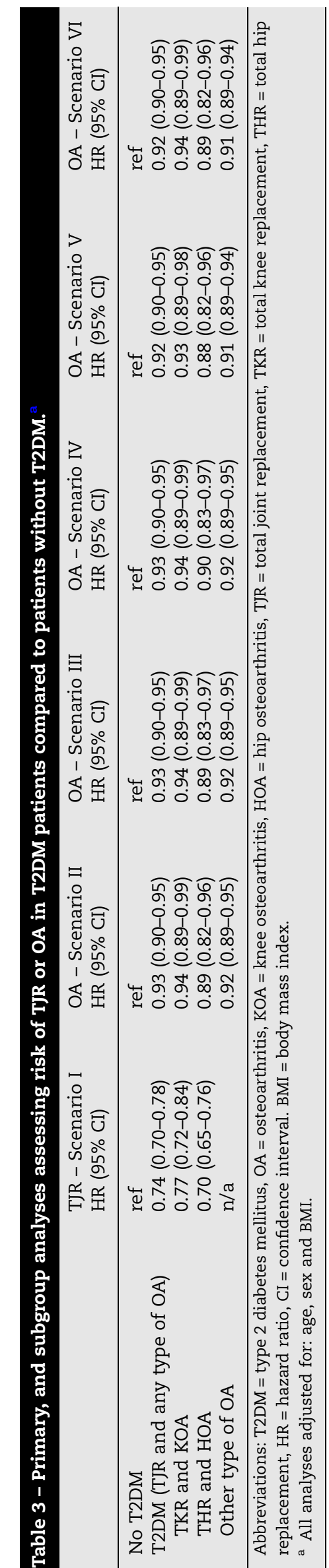

tions associated with surgery in T2DM patients compared to patients without T2DM [11]. Previous studies have shown that high HbA1c levels are associated with more complications and more surgical site infections [12-14]. Furthermore, HbA1c levels have been associated with higher mortality rates in non-orthopaedic surgical procedures [15]. Based on these increased risks of complications, surgeons may be less tempted to operate on patients with T2DM. Consequently, some T2DM patients may not undergo TJR due to a high risk of surgical complications even though they may have OA. In contrast to TJR, this type of bias is unlikely to have affected the recording of an OA-diagnosis potentially explaining the $20 \%$ difference found in this study.

Furthermore, we found no differences in the risk of OA when a latency period up to 10 years after start of follow-up was added. In fact, the HR remained the same with a latency period varying from 0 to 10 years after start of follow-up. The results were similar for the overall and the joint-specific subgroup analyses. Although the date of OA diagnosis is estimated to reflect the actual date of onset with an average delay of 7.7 years [16], the results from this study suggest that the impact of misclassification the date of onset of OA is limited.

This study has several strengths. First, by using the world's largest primary care database representative for the British population we were able to analyse a population of over 140,000 T2DM patients and an equal number of randomly selected controls. Second, to our knowledge, this was the first study evaluating the effect of timing of the outcome by comparing different proxies, when evaluating the association between T2DM and OA. However, as with all studies there are some limitations to consider. First, a NIAD prescription was used as a proxy for T2DM. This proxy, however, does not include early stage T2DM patients as they are generally treated with lifestyle interventions, rather than pharmacological therapy. However, these early stage patients may have had deregulated glucose levels for a shorter period of time than the T2DM population using anti-hyperglycaemic drug. The bio-pathological effects suggested to be involved in the development and progression of OA may therefore be limited in this population. Consequently, the effect of not including these early stage patients is probably limited. Second, this study is based on the assumption that once treated with a single NIAD, the patient has T2DM and will continue to have T2DM during the entire follow-up. Although T2DM is suggested to be reversible in some cases [19], it is generally considered to be an enduring progressive disease, despite the use of glucose-lowering treatment [20]. Furthermore, NIADs are selectively prescribed to treat T2DM. Consequently, it is unlikely that non-T2DM patients were misclassified as T2DM patients. Finally, TJR is a generally well registered outcome, as this is a major medical event that is unlikely to go unnoticed. However, this is possibly not the case for the outcome "OA diagnosis", as the codes for an OA diagnosis in the CPRD have not yet been validated, and potentially codes for RA and OA may have been used interchangeably. Consequently, misclassification of this outcome may have occurred. This misclassification may be differential, as T2DM patients visit their GP on a regular basis, and therefore the threshold to address OA related issues may be relatively lower in these 


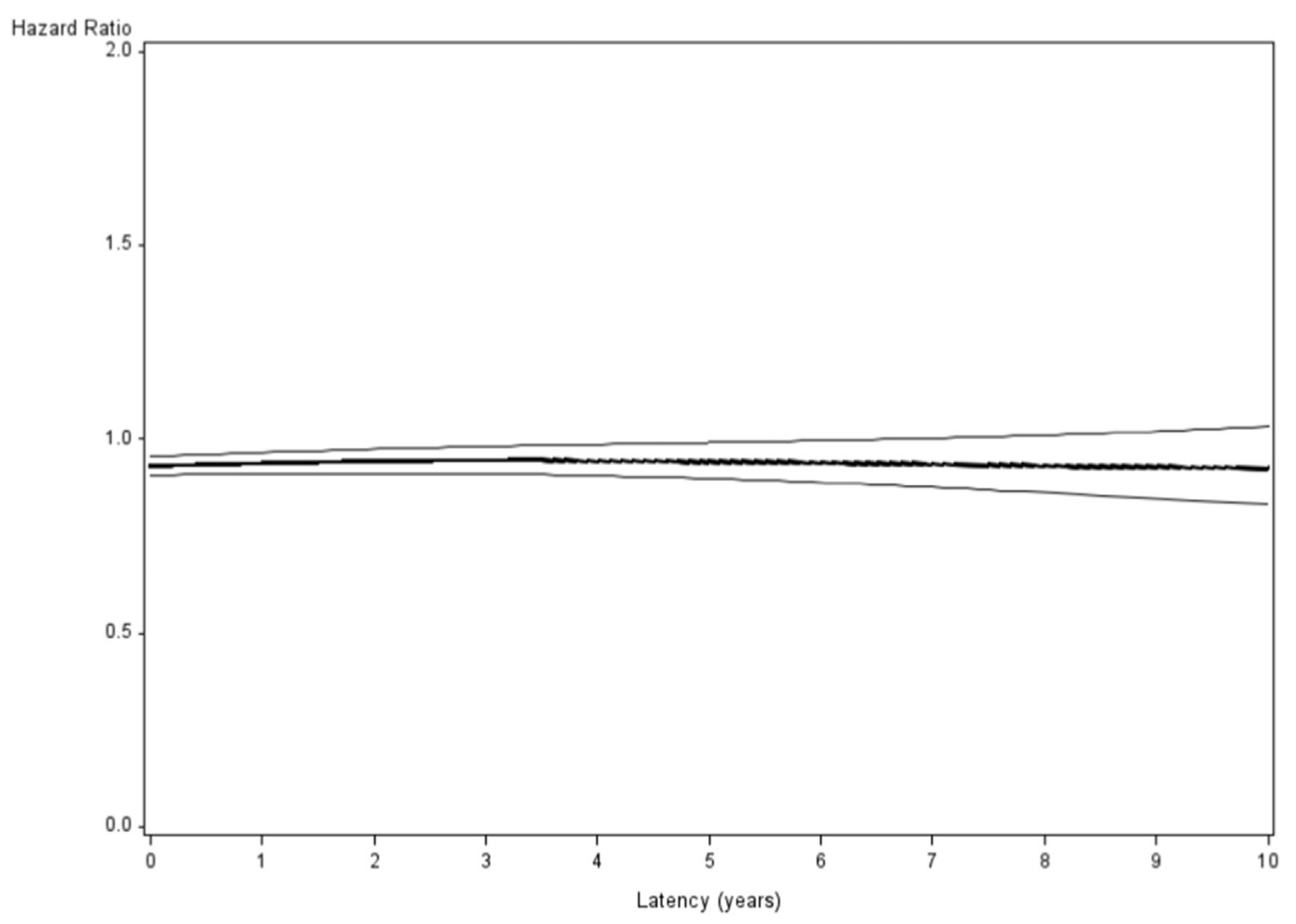

Fig. 3 - Risk (HR (bold line) and 95\% CI) of OA in T2DM patients compared to patients without T2DM with varying latency period after start of follow-up. Analyses conducted in Scenario VI. Adjusted for: age, BMI, and sex. Abbreviations: T2DM = type 2 diabetes mellitus, $\mathrm{OA}=$ osteoarthritis, $\mathrm{HR}=$ hazard ratio, $\mathrm{CI}=$ confidence interval, $\mathrm{BMI}=$ body mass index.

patients compared to healthy individuals. Alternatively, GPs may be less likely to register a secondary diagnosis (i.e. OA) if they already have a primary diagnosis (i.e. T2DM). Overall, there may be counteracting possibilities for differential misclassification and the effects on the results of this study may therefore be limited.

In conclusion, the use of either a surgical or a diagnostic proxy for OA when examining the association between T2DM and OA resulted in a reduced risk of the outcome. However, the point estimate for TJR was approximately $20 \%$ lower than the OA diagnosis. This may have been caused by selection bias as especially severe T2DM patients may not be eligible to undergo elective joint surgery. It should be emphasized that due to the methodological nature of this study, a limited number of potential confounders were included, and, consequently, the presented risk estimates should be interpreted as comparative numbers only, not as absolute risk estimates.

\section{Conflict of interest/Acknowledgements}

$\mathrm{JN}, \mathrm{OK}$, and FV have no conflicts of interest to declare. BB receives research grants to his department from Pfizer and Roche and occasionally speakers honoraria form Pfizer, Roche, Abbvie and MSD. AB receives research grants to her department from Amgen Abbvie, Pfizer and Merck and occasionally speakers honoraria from Pfizer, UCB and Sandoz. PD has received unrestricted grants from NWO, EU and nutritional industry for research unrelated to this topic.

\section{Appendix A. Supplementary material}

Supplementary data to this article can be found online at https://doi.org/10.1016/j.diabres.2019.01.021.

REFERENCES

[1] Arthritis Research UK. Osteoarthritis in general practice; 2013.

[2] Learmonth ID, Young C, Rorabeck C. The operation of the century: total hip replacement. Lancet 2007;370 (9597):1508-19.

[3] Schett G, Kleyer A, Perricone C, Sahinbegovic E, Iagnocco A, Zwerina J, et al. Diabetes is an independent predictor for severe osteoarthritis: results from a longitudinal cohort study. Diabetes Care 2013;36:403-9.

[4] Nieves-Plaza M. Association of hand or knee osteoarthritis with diabetes mellitus in a population of Hispanics from Puerto Rico. J Clin Rheumatol 2013;19(1):1-6.

[5] Williams MF, London DA, Husni EM, Navaneethan S, Kashyap SR. Type 2 diabetes and osteoarthritis: a systematic review and meta-analysis. J Diabetes Complicat 2016;30(5):944-50.

[6] Louati K, Vidal C, Berenbaum F, Sellam J. Association between diabetes mellitus and osteoarthritis: systematic literature review and meta-analysis. RMD Open 2015;1(1):e000077.

[7] Nielen JT, Emans PJ, Dagnelie PC, Boonen A, Lalmohamed A, de Boer A, et al. Severity of diabetes mellitus and total hip or knee replacement: a population-based case-control study. Medicine (Baltimore) 2016;95(20):e3739. 
[8] Driessen JH, van den Bergh JP, van Onzenoort HA, Henry RM, Leufkens HG, de Vries F. Long-term use of dipeptidyl peptidase-4 inhibitors and risk of fracture: a retrospective population-based cohort study. Diabetes Obes Metab 2017;19 (3):421-8.

[9] Gamble JM, Chibrikov E, Twells LK, Midodzi WK, Young SW, MacDonald D, et al. Association of insulin dosage with mortality or major adverse cardiovascular events: a retrospective cohort study. Lancet Diabetes Endocrinol 2017;5 (1):43-52.

[10] Nielen JT, de Vries F, Dagnelie PC, van den Bemt BJ, Emans PJ, Lalmohamed A, et al. Use of thiazolidinediones and the risk of elective hip or knee replacement: a population based casecontrol study. Br J Clin Pharmacol 2016;81(2):370-8.

[11] Tsang ST, Gaston P. Adverse peri-operative outcomes following elective total hip replacement in diabetes mellitus: a systematic review and meta-analysis of cohort studies. Bone Joint J 2013;95-B(11):1474-9.

[12] Stryker LS, Abdel MP, Morrey ME, Morrow MM, Kor DJ, Morrey BF. Elevated postoperative blood glucose and preoperative hemoglobin A1C are associated with increased wound complications following total joint arthroplasty. J Bone Joint Surg Am 2013;95. 808-814S1-S2.

[13] Harris AH, Bowe TR, Gupta S, Ellerbe LS, Giori NJ. Hemoglobin $\mathrm{A} 1 \mathrm{C}$ as a marker for surgical risk in diabetic patients undergoing total joint arthroplasty. J Arthroplast 2013;28(8 Suppl.):25-9.
[14] Wukich DK, Crim BE, Frykberg RG, Rosario BL. Neuropathy and poorly controlled diabetes increase the rate of surgical site infection after foot and ankle surgery. J Bone Joint Surg Am 2014;96:832-9.

[15] Chorin E, Finkelstein A, Banai S, Aviram G, Barkagan M, Barak $\mathrm{L}$, et al. Impact of diabetes mellitus and hemoglobin A1C on outcome after transcatheter aortic valve implantation. Am J Cardiol 2015;116:1898-903.

[16] MacDonald KV, Sanmartin C, Langlois K, Marshall DA. Symptom onset, diagnosis and management of osteoarthritis. Health Rep 2014;25(9):10-7.

[17] Herrett E, Gallagher AM, Bhaskaran K, Forbes H, Mathur R, van Staa T, et al. Data resource profile: Clinical Practice Research Datalink (CPRD). Int J Epidemiol 2015 Jun;44 (3):827-36. https://doi.org/10.1093/ije/dyv098. Epub 2015 Jun 6.

[18] De Jong RG, Gallagher AM, Herrett E, Masclee AA, JanssenHeijnen ML, de Vries F. Comparability of the age and sex distribution of the UK Clinical Practice Research Datalink and the total Dutch population. Pharmacoepidemiol Drug Saf 2016;25(12):1460-4.

[19] Taylor R. Type 2 diabetes: etiology and reversibility. Diabetes Care 2013;36(4):1047-55.

[20] Turner RC, Cull CA, Frighi V, Holman RR. UK Glycemic control with diet, sulfonylurea, metformin, or insulin in patients with type 2 diabetes mellitus: progressive requirement for multiple therapies (UKPDS 49). JAMA 1999;281:2005-12. 